\title{
COMPETITIVE DEVELOPMENT OF ENERGY COGENERATION SYSTEMS IN CONDITIONS OF ECONOMIC IMBALANCES
}

\author{
ALEXEY DOMNIKOV, MIKHAIL KHODOROVSKY \& LIUDMILA DOMNIKOVA \\ Academic Department of Banking and Investment Management, Ural Federal University named after the First \\ President of Russia B.N. Yeltsin, Russia.
}

\begin{abstract}
The paper presents the results of a study in the field of a comprehensive economic assessment of the competitive advantages of cogeneration power sources in the context of economic imbalances.

In the course of the study, the theoretical and methodological aspects of the competitive development of energy cogeneration systems were studied. Thus, it is proved that for the methodological support of the process of constructing strategic tasks in energy-generating companies operating in energy cogeneration systems, it is necessary to develop specialized industry methodological tools for assessing business processes in the field of cogeneration. In addition, the revealed multilevel specifics of positioning cogeneration energy sources in the territorial energy market under the conditions of economic imbalances required creation of a special methodology to take into account the peculiarities of the development of energy cogeneration systems with the help of which it is possible to study the nature of the impact of economic imbalances that disrupt the normal course of the investment process in energy cogeneration systems.

Testing of the developed methodology showed that the relationship between the centralized and distributed energy cogeneration systems can be different depending on the market conditions and the state of the competitive environment. Thus, in addition to traditional steam turbine plants, in a centralized energy cogeneration system, priority should be given to cogeneration gas plants, as the most competitive in terms of efficiency and maneuverability, and in a distributed - to cogeneration gas turbine plants, mainly built on the basis of local boiler houses.

Keywords: centralized energy sources, competition, efficiency, mathematical economic models, power industry, reliability, risks, strategy, uncertainty.
\end{abstract}

\section{INTRODUCTION}

The opportunities for developing economies are largely determined by the capacity and condition of energy systems. In the context of growing institutional and market risks, a substantial modernization of the energy infrastructure is required to improve the competitiveness of the Russian economy and to meet the requirements of the new industrialization. Economic imbalances and uncertainty, characterized primarily by the instability of energy demand, reduced profitability, and, as a result, low investment attractiveness of the energy business in the energy generation sector exponentially increase interest in studying the problems related to improving competitiveness of power-generating facilities. This is especially important for the territorial power generation systems, where cogeneration power sources have penetrated both the electric and thermal energy markets. Moreover, they comprise a link between the structured electric power industry and industrial consumers competing in domestic and foreign markets.

The dominating current trends in new industrialization have created new conditions which are characterized by conflicting interests of electricity market participants and a high degree of uncertainty. This results in a change of previous priorities to new ones: reliability and energy efficiency have become two key challenges, as the most promising strategies which may help to improve the competitiveness of centralized and distributed energy cogeneration 
systems, to eliminate the conflicts between the professional business entities in the power industry and to overcome the specific conditions created by economic imbalances.

The emerging imbalances in the economic system have formed a specific business environment for energy generation, which is characterized by insufficient growth rates and problems associated with raising the competitiveness. This reveals lack of scientific and methodological support in the field of sustainable development of cogeneration systems that can take into account the peculiarities of territories in which energy consumers are located. The proposed structural changes in the course of new industrialization should reduce economic imbalances by increased efficiency of the regional fuel and energy complex. As a result of successful implementation of the territorial development programs and reduction of economic risks for power companies, these processes should contribute to improving the investment attractiveness of the energy business.

\section{CONCEPT OF A SYSTEM FOR MONITORING ECONOMIC IMBALANCES}

Objective assessment of the processes taking place in the economy and, in particular, in the energy market requires development of a constantly functioning system of information and analytical support for the decision-making process. Such a system can be based on monitoring the economic imbalances, which allows analyzing the possibility for a power company to sustainably differentiate itself from the competition and to implement corresponding benefits.

Monitoring of economic imbalances is an information and analytical tool that improves the quality and effectiveness of the decision-making system by identifying the risks that may cause economic imbalances.

Monitoring of economic imbalances is conducted with the following aims:

- to permanently monitor the processes, phenomena, and status (parameters) of specific objects and systems in order to minimize the development risks and

- to analyze, aggregate, and generalize primary indicators, to calculate (or form on their basis) the final product, i.e. an array of indicators, and their time series and comparative values characterizing the state of power cogeneration systems.

The above aims allow determining the following tasks:

- to identify the composition, sources, nature, and severity of the risks associated with the development of power cogeneration systems, to consider the peculiarities of the risk manifestation and further localization and

- to prepare the necessary information for subsequent diagnostics of the competitiveness of cogeneration power sources and to select the most effective solutions to neutralize the risks associated with the development of energy cogeneration systems.

Based on the nature of the tasks to be solved, Fig. 1 shows a generalized diagram for monitoring economic imbalances, which includes two interrelated stages: (1) data processing and (2) computational analysis.

During the first stage, it is important to collect complete, reliable, and relevant information which should be initially processed and systematized in time. The computational analysis makes it possible to study and process the obtained primary data for each monitored object, taking into account the peculiarities of the competitive environment in the territorial energy 


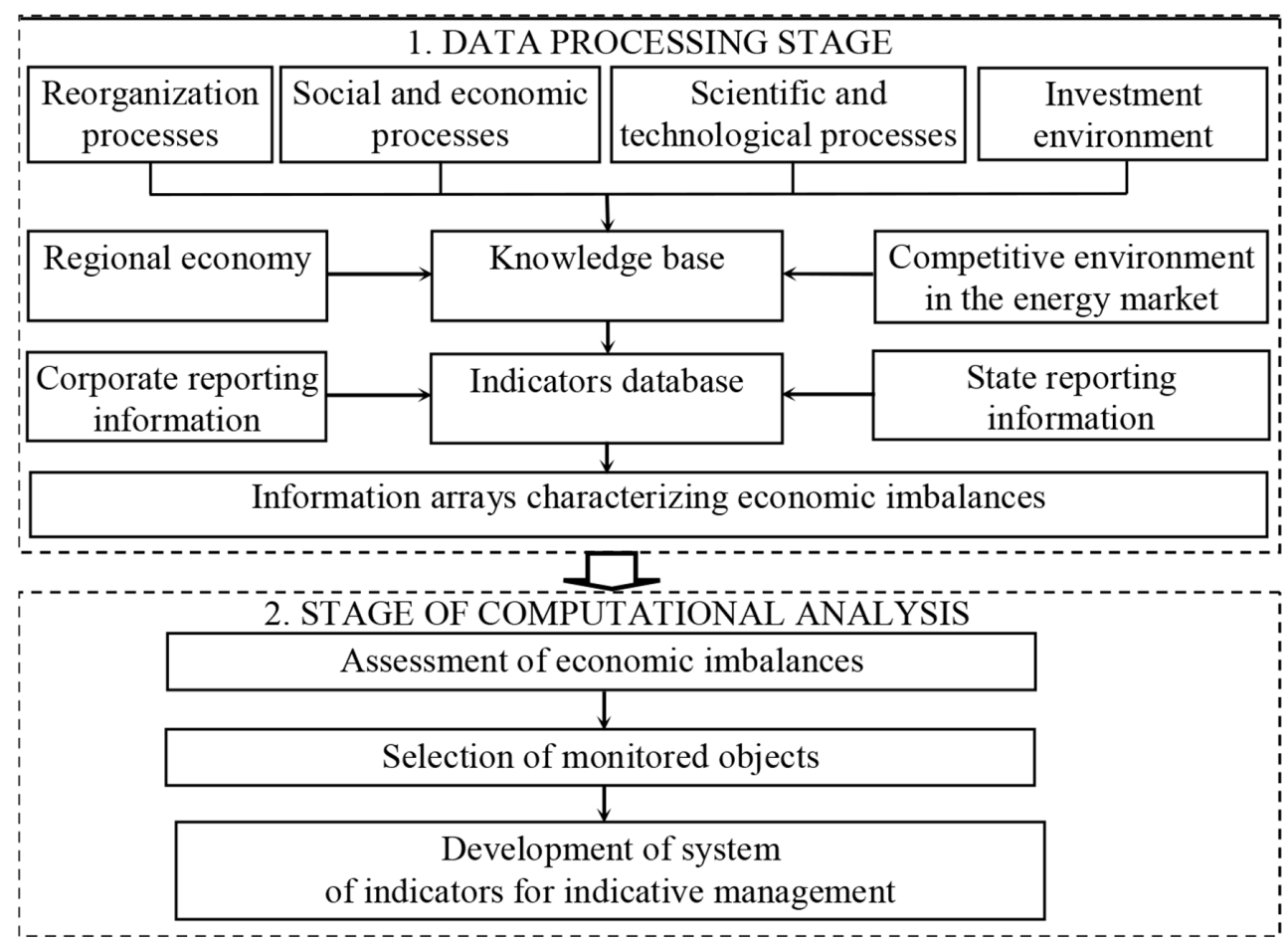

Figure 1: Diagram for monitoring of economic imbalances.

market and ensuring comparability of the calculated indicators for subsequent diagnostics of the competitiveness of cogeneration power sources. In general, these stages allow the authors to select and track the indicators, on the basis of which the business environment of the territorial energy market will be further monitored.

All the above mentioned allow the authors to briefly formulate the main provisions of the concept describing the formation and functioning of the economic imbalances monitoring system:

- Monitoring includes (as industry-dependent components) observation, evaluation, and analysis of the conditions for reliable and sufficient supply of electricity and heat in the territory.

- Monitoring includes analysis and assessment of the competitive capabilities of cogeneration power sources.

- The factual basis for monitoring should be corporate, sectoral, and state statistics.

It should be noted that monitoring effectiveness largely depends on the quality, thoroughness, and technology used for assessing the economic imbalances. To achieve these aims, the selected monitored objects are differentiated (taking into account the development scenario of the power-generating facilities in a competitive environment) and subdivided into seven groups that conventionally describe the business environment in the territorial energy market, including: energy generation, energy transmission, energy market conditions, energy 
efficiency, reliability, economy, and finances. Such differentiation of the monitored objects makes it possible to improve the quality of the information received and to take into account the entire array of risks associated with the development of energy cogeneration systems, since these risks reduce competitiveness of power companies. Besides, the need in such differentiation is dictated by

- the necessity to simultaneously assess the absolute and relative values of all indicators;

- the multidimensionality of the monitored objects; and

- the highest degree of impact on the formation and development of competitive opportunities.

Figure 2 shows the offered structure of the objects selected for monitoring economic imbalances and a group of the corresponding indicators. The chosen groups of monitored objects are the main components which shape the competitiveness of power-generating facilities, both in the territorial energy market and in the investment market.

Briefly, each group of the objects selected for monitoring of economic imbalances can be characterized as follows.

The first group of the monitored objects characterizes the possibility to completely satisfy the need for electric and thermal energy using cogeneration power sources.

The second group of the monitored objects shows the state and prospects for the development of the transport and transmission systems which greatly contribute to the competitiveness of cogeneration power sources, especially in the thermal energy market.

A group of objects reflecting the energy market conditions shows the level of electric and thermal energy consumption, including the maximum load. Electrical connections show the level of deficit (excess) of electricity in the territory and the volume of supplies from neighboring regions necessary to cover the maximum load.

The fourth group of the monitored objects that characterize energy efficiency includes indicators reflecting the volume of fuel consumption by the type of fuels and by each cogeneration power source. In addition, it shows the level of losses during transmission of electric and thermal energy.

The group of objects characterizing reliability includes indicators reflecting the intensity of use of each cogeneration power source and the reserves of coal and fuel oil. Besides, the performance of communication systems supporting the power industry is considered, including the capacity of power lines, heat distribution networks, and gas pipelines. Reliability is measured by the indicators which reflect the cases where electric or thermal energy is undersupplied to consumers due to disruption of the production cycle mostly due to accidents, unplanned shutdowns, and downtime.

The economic group of monitored objects is characterized by technical and economic indicators showing the level of costs, productivity, return on assets, and depreciation of fixed assets. An important component of this group is a subset of indicators describing the investments in new construction and technical re-equipment of cogeneration power sources, as well as the environmental protection investments. The activation of the investment processes is largely affected by the structure of investment sources. Personnel development shows the level of expenses allocated to employee training and re-training.

The financial group of the monitored objects contains the key indicators of investment attractiveness. These indicators include: financial stability, liquidity, business activity, profitability, and yields of securities issued by power-generating facilities. The financial potential 


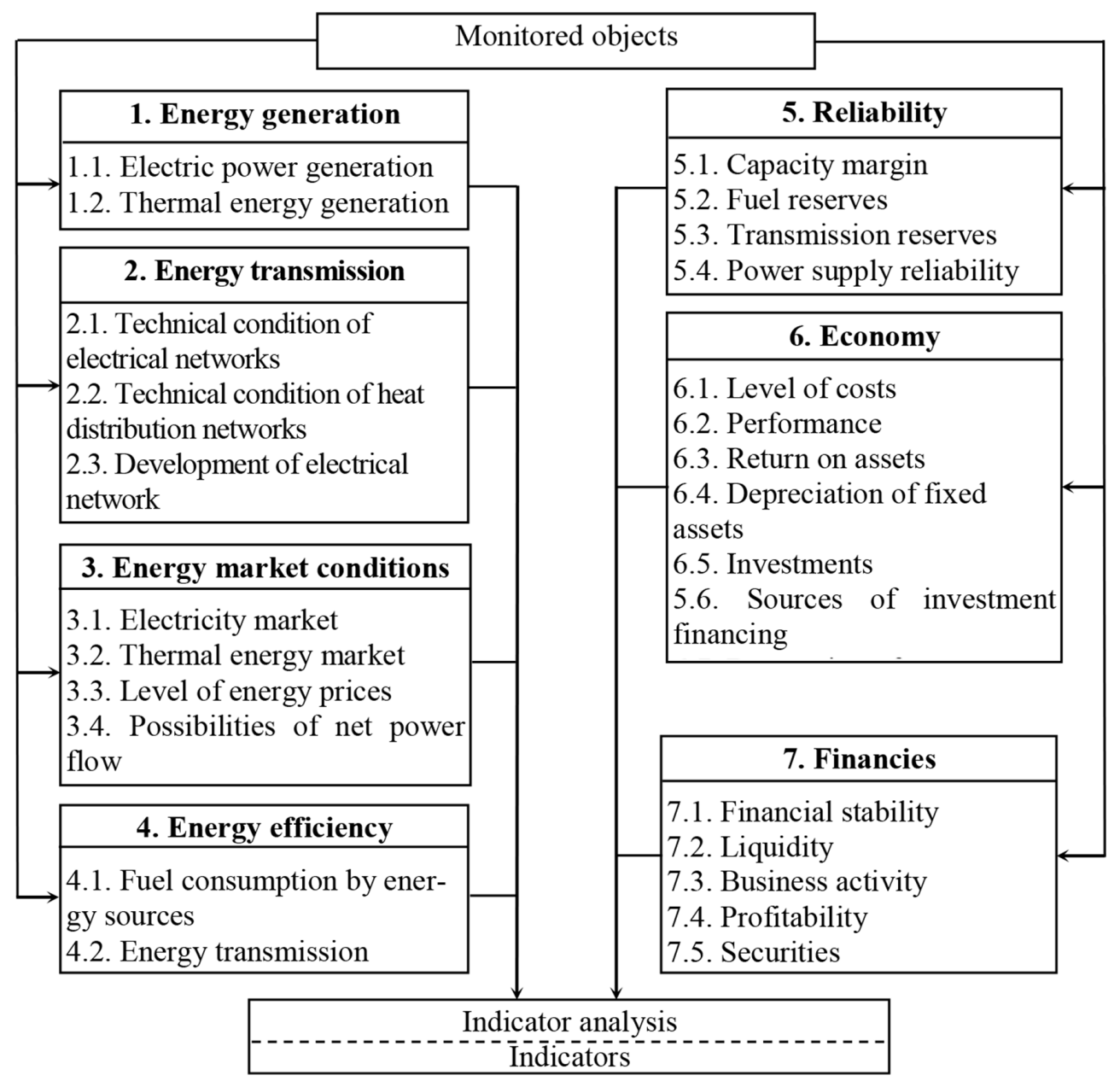

Figure 2: Structure of objects selected for monitoring of economic imbalances.

is determined by the financial results achieved during the reporting period (the amount of profit or loss received, the level of profitability, etc.) and, in addition, is characterized by the structure of capital and sources of funding.

Monitoring economic imbalances results in compilation of databases, which allow the authors to select the arrays of indicators that are necessary for conducting diagnostics of power-generating company competitiveness.

\section{THEORETICAL AND METHODOLOGICAL BASIS FOR CALCULATING THRESHOLD VALUES WHICH DEFINE COMPETITIVENESS RATINGS OF COGENERATION POWER SOURCES}

As it is shown in $[1,5]$, assessment of competitive advantages of cogeneration and conditions in the territorial energy market requires elaboration of methodological tools which make it possible to determine the competitiveness ratings of cogeneration power sources. This problem can be solved using an analytical procedure - indicator analysis. Its main purpose is to 
determine the threshold (i.e. the maximum permissible levels) of indicators, the non-compliance with which (excess or failure to achieve) will lead to negative processes. The analytical tools developed by the authors for indicative analysis are based on the ideas of cluster and discriminant analysis.

The main objective of the initial cluster analysis incorporates two most important aspects: (1) elaboration of a uniform measuring unit covering a number of features and (2) quantitative solution to the issue of grouping the monitored objects [11].

The used procedure of cluster analysis stipulates that all distinctive features are agglomerated (with the help of some 'metric') into one quantitative indicator of similarity (difference) of the grouped objects. However, without a preliminary quality analysis, it is impossible to start investigation; that is why, certain distinctive features are combined into one group. The said features are usually agglomerated using 'similarity metric' - Euclidean distance.

The most common hierarchical clustering technique is Ward's method [9, 12, 13]. This clustering method is based on Ward's linkage algorithm and is essentially a ratio containing measured distances $d_{i j}$. Let us consider the vector of indicators $X=\left(X_{1}, X_{2}, \ldots, X_{n}\right)$. The square of the standard Euclidean distance between points $X_{i}$ and $X_{j}$ is given by the formula:

$$
d_{i j}^{2}=\left(X_{i}-X_{j}\right)^{T} \cdot\left(X_{i}-X_{j}\right)
$$

According to Ward's method [9], the intragroup sum of squared deviations (which is understood as the sum of squared distances between each point [object] and the centroid of the cluster containing this object) is used as the objective function. This method provides a sequential procedure, according to which at each step, it is necessary to optimize the objective function (find the optimal pair of clusters to merge).

Merging of clusters $I$ and $J$ results in increase of the objective function by $W_{I J}$, which is given by the equation:

$$
W_{I J}=\frac{n_{I} \cdot n_{J}}{n_{I}+n_{J}} \cdot\left(\bar{X}_{I}-\bar{X}_{J}\right)^{T} \cdot\left(\bar{X}_{I}-\bar{X}_{J}\right)=\frac{n_{I} \cdot n_{J}}{n_{I}+n_{J}} \cdot d_{I J}^{2},
$$

where $d_{I J}^{2}=\left(\bar{X}_{I}-\bar{X}_{J}\right)^{T} \cdot\left(\bar{X}_{I}-\bar{X}_{J}\right)$.

Starting from the matrix of squared Euclidean distances $D=\left\{d_{i j}^{2}, i=1,2, \ldots, n ; j=1,2, \ldots, n\right\}$, the procedure consists of merging such clusters $I_{P}$ and $I_{Q}$, for which $d_{P Q}^{2}=2 W_{P Q}$ is minimal.

The final algorithm, according to which the objects are grouped, shall be visualized as follows:

1. $d_{P Q}^{2}=\min \left\{d_{i j}^{2}\right\}, i=1, \ldots, j-1 ; j=2, \ldots, n ; n_{i}>0 ; n_{j}>0$ is calculated.

2. The increase of the objective function after merging of two clusters $I_{P}$ and $I_{Q}$ is calculated by the formula:

$$
W_{P Q}=\frac{1}{2} \cdot d_{P Q}^{2}
$$

3. $I_{P}$ is substituted by $I_{P}^{\prime}$; line $\left\{d_{i P}^{2}\right\}$ and column $\left\{d_{P j}^{2}\right\}$ of $D$ matrix are recalculated by eqn (4) $i=1,2, \ldots, P-1 ; n_{i}>0 ; j=P+1, \ldots, n ; j \neq Q ; n_{j}>0$ 


$$
\begin{aligned}
d_{i P}^{2} & =2 W_{i r}=\frac{2}{\left(n_{i}+n_{r}\right)} \cdot\left[\left(n_{i}+n_{P}\right) W_{i P}+\left(n_{i}+n_{Q}\right) W_{i Q}-n_{i} W_{P Q}\right] \\
& =\frac{1}{n_{i}+n_{r}}\left[\left(n_{i}+n_{P}\right) d_{i P}^{2}+\left(n_{i}+n_{Q}\right) d_{i Q}^{2}-n_{i} d_{P Q}^{2}\right] .
\end{aligned}
$$

4. The authors consider that $n_{P}=n_{P}+n_{Q}$ and $n_{Q}=0$; then, the $I_{Q}$ cluster turns into an invalid set of values.

5. The elements of cluster $I_{Q}$ are included in cluster $I_{P}^{\prime}$; then, the whole procedure is repeated $n-2$ times starting from the first step.

The second procedure, discriminant analysis, is based on determination of canonical coordinates in the original space of features (indicators) that satisfy the following criterion:

$$
F=\frac{D_{1}}{D_{2}} \rightarrow \max
$$

where $D_{1}$ is the between-class dispersion and $D_{2}$ is the within-class dispersion.

When determining the threshold parameters and interrelated indicators, the multivariate normal distribution is expressed mathematically in the form of covariance matrix as follows:

$$
p(x)=(2 \pi)^{-\frac{m}{2}}|S|^{-\frac{1}{2}} \exp \left[-\frac{1}{2}(X-)^{T} S^{-1}(X-M)\right],
$$

where $M$ is the mean vector of indicator values in a training set for each class, $S$ is the covariance matrix, and $X$ is the vector of parameters describing points in space $\left\{R^{m}\right\}$.

The cost of taking a correct decision is usually considered as zero. The losses from incorrect classification and a priori probabilities of the appearance of an object of this or that class in the problem to be solved can be taken as equal. Then, in accordance with the Bayesian information criterion, the threshold value separating one class from another (e.g. the classes of normal and transient statuses), by an independent parameter, can be determined from the equation:

$$
\frac{\int_{-\infty}^{x_{T}^{0}} p_{N}(x) d x}{\int_{x_{T}^{0}}^{+\infty} p_{T}(x) d x}=1
$$

Having substituted its variables with expressions (eqn (6)) for a one-dimensional space and having added the final set of transformations (using the properties of the function of the normal distribution), the following integral equation can be obtained:

$$
\int_{\mu_{N}}^{x_{T}^{0}} \frac{1}{\sigma_{N} \sqrt{2 \pi}} \exp \left[-\frac{\left(x-\mu_{N}\right)}{2 \sigma_{N}^{2}}\right] d x=\int_{x_{T}^{0}}^{\mu_{T}} \frac{1}{\sigma_{T} \sqrt{2 \pi}} \exp \left[-\frac{\left(x-\mu_{T}\right)^{2}}{2 \sigma_{T}^{2}}\right] d x,
$$


where $\mu_{N}$ and $\mu_{T}$ are the expected threshold values.

With respect to $x_{T}^{0}$, the equation can be solved by means of numerical integration. Based on the research performed, its solution shall be as follows (with a decrease of the integration step size):

$$
\exp \left(-\frac{\left(x-\mu_{N}\right)^{2}}{\sigma_{N}^{2}}\right)=\exp \left(-\frac{\left(x-\mu_{T}\right)^{2}}{\sigma_{T}^{2}}\right) .
$$

Thus, the equation of the boundary surface of $F$ classes in multidimensional space will look as follows:

$$
\left(X-M_{N}\right)^{T} S_{N}^{-1}\left(X-M_{N}\right)=\left(X-M_{T}\right)^{T} S_{T}^{-1}\left(X-M_{T}\right) .
$$

The threshold values are determined as the coordinates of point $A$, in which the surfaces of $F$ classes intersect the line running through the cluster centers with coordinates $M_{N}$ and $M_{T}$ (see Fig. 3).

In accordance with the equations of a line passing through two points in space [10], the following formula is obtained:

$$
\frac{X-M_{N}}{M_{T}-M_{N}}=b .
$$

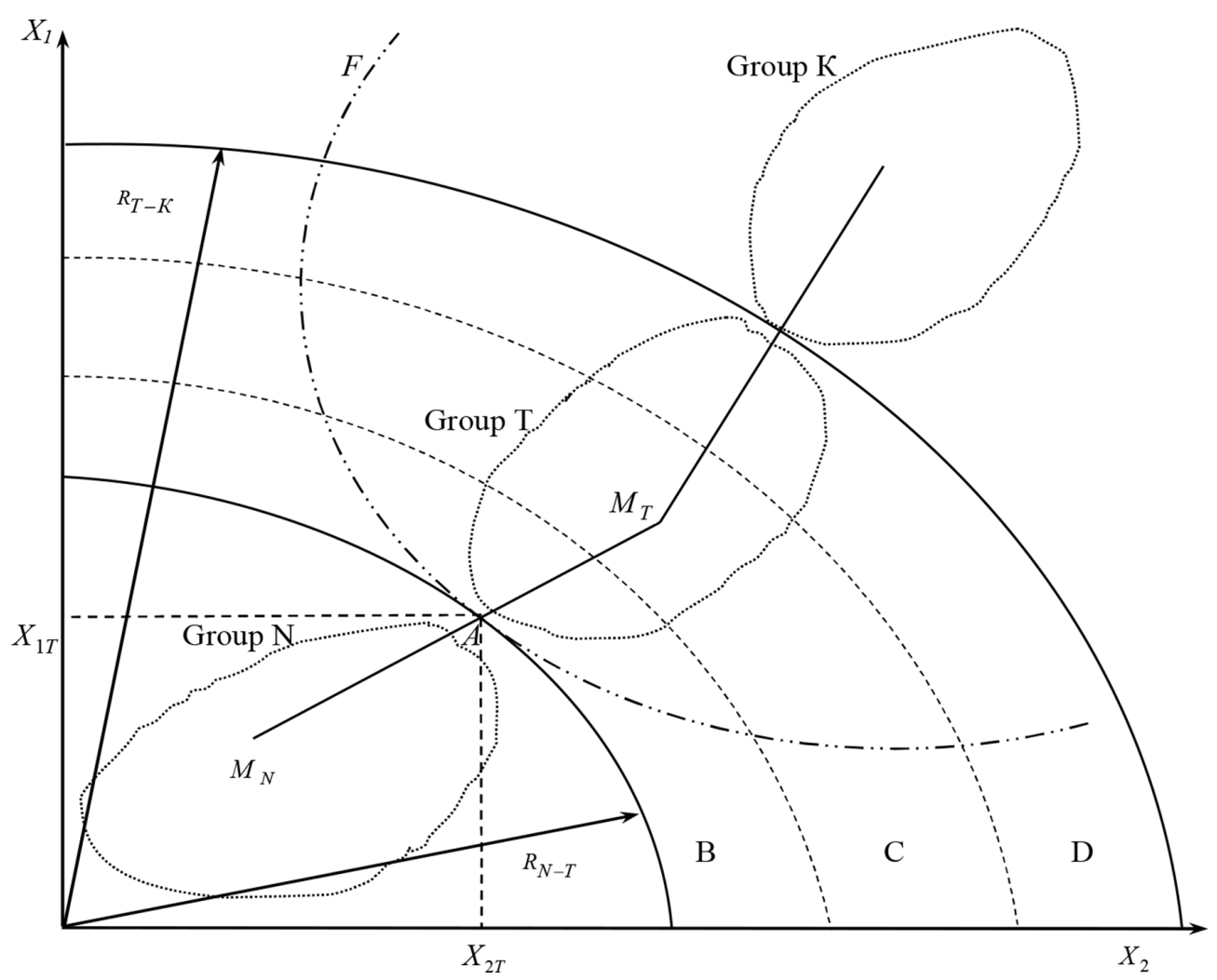

Figure 3: Diagram of object status classification (a fragment for a transient group is shown). 
Having made the required transformations, the equation for the threshold coordinates which separate the classes of normal and transient statuses can be obtained:

$$
X=b\left(M_{T}-M_{N}\right)+M_{N},
$$

where $b$ is a parameter of a straight line.

After the necessary transformations, the following quadratic equation is obtained with respect to $b$ :

$$
b^{2}\left(C_{N}-C_{T}\right)+2 b C_{T}-C_{T}=0,
$$

where $C_{N}=\left(M_{T}-M_{N}\right)^{T} S_{N}^{-1}\left(M_{T}-M_{N}\right), C_{T}=\left(M_{T}-M_{N}\right)^{T} S_{T}^{-1}\left(M_{T}-M_{N}\right)$.

The equation root which satisfies the condition $0 \leq b_{0} \leq 1$ corresponds to the point of intersection with the straight line which separates the surfaces. Using the root and eqn (13), the coordinates of the point on the surface intersection and the line joining the cluster centers of the normal and transient statuses can be determined ( $\left.X_{T}^{0}\right)$ (see Fig. 3):

$$
X_{T}^{0}=b_{0}\left(M_{T}-M_{N}\right)+M_{N} .
$$

To determine the coordinates of the intersection point between the boundary surface and the straight line connecting the cluster centers of the transient $(\mathrm{T})$ and the critical (K) statuses, a similar calculation procedure is used.

The obtained coordinates of the intersection points are subsequently used to construct the radii of the boundary surface - a hypersphere. The radius length will correspond to the threshold values.

Table 1 shows the classification of statuses at all levels of indicative analysis $[1,5]$.

\section{APPLICATION OF THE INDICATIVE ANALYSIS METHOD}

The methodological approach to indicator analysis was tested using the competitiveness diagnostics carried out for individual subsidiaries of T Plus, JSC, a Russian electricity generation company (http://www.tplusgroup.ru). The choice of this company as an object of indicator analysis is explained by the fact that the level of competitiveness of its cogeneration power sources largely determines the development of the energy cogeneration systems in the territorial energy market. Moreover, the emerging economic imbalances can lead to

Table 1: Classification of statuses as per the level of competitiveness.

\begin{tabular}{lll}
\hline Groups & LoC & Designation \\
\hline Normal (N) & Weak & $A$ \\
& Low & $B$ \\
Transient (T) & Medium & $C$ \\
& Unstable & $D$ \\
& High & $E$ \\
Critical (K) & Ominous & $F$ \\
& Grave & $G$ \\
\hline
\end{tabular}

LoC - level of competitiveness. 
disturbances which can increase the risks, threatening further development of the power-generating company and, accordingly, can reduce its investment attractiveness.

T Plus, JSC plays an important role in the economy of the Ural region. The length of its heat distribution networks is about $18,000 \mathrm{~km}$, the total capacity of power-generating sources is more than $15.5 \mathrm{GW}$, the thermal capacity of power plants is more than $55,000 \mathrm{Gcal} / \mathrm{h}$, and the total number of personnel exceeds 47,000 employees.

The status of each subsidiary of T Plus, JSC is classified by its competitiveness rating, taking into account the specifics of each array of indicators and the situation as a whole. With this aim, the authors applied the indicative classification algorithm consisting of 12 stages the diagram is shown in $[1,5]$.

Based on the statistical data provided in the corporate reporting of the energy company for 2019, a series of simulation calculations have been performed. At the initial stage, to determine the competitiveness rating of each subsidiary of the energy-generating company, the values of normalized thresholds have been calculated for each level of competitiveness, taking into account each array of indicators (see Table 2).

The diagnostic results show (see Table 3) that Sverdlovsky, Permsky, and Nizhegorodsky subsidiaries of T Plus, JSC have the highest competitiveness level, while Mari El, Komi, and Mordovia power plants are at the lowest level.

The results obtained indicate the need to accelerate the development of individual subsidiaries of T Plus, JSC to eliminate accumulated negative factors which in the future can lead to: (1) shortage of electric and thermal energy in the territory; (2) limitation of energy supply to consumers; (3) loss of competitive advantages in the territorial energy market; and (4) overpriced electric and thermal energy.

The most optimal decision to minimize the negative impact of economic imbalances is to improve the fuel consumption strategy based on modern solid fuel combustion technologies that have high economic and environmental efficiency. This means: (1) the use of solid fuel combustion technology in circulating fluidized bed boilers; (2) promotion of cogeneration combined cycle plants; and (3) construction of highly maneuverable renewable energy sources which may work in the peak load conditions. Ultimately, these measures can increase the resistance of the energy-generating company to the impact of economic imbalances.

Table 2: Normalized threshold values.

\begin{tabular}{lcccccc}
\hline & \multicolumn{7}{c}{ Threshold level } \\
Array of indicators & $\boldsymbol{B}$ & $\boldsymbol{C}$ & $\boldsymbol{D}$ & $\boldsymbol{E}$ & $\boldsymbol{F}$ & $\boldsymbol{G}$ \\
\hline Energy generation & 0.123 & 0.328 & 0.439 & 0.604 & 0.668 & 0.793 \\
Energy transmission & 0.104 & 0.310 & 0.375 & 0.426 & 0.548 & 0.754 \\
Energy market conditions & 0.127 & 0.256 & 0.377 & 0.464 & 0.581 & 0.726 \\
Energy efficiency & 0.273 & 0.353 & 0.421 & 0.515 & 0.626 & 0.735 \\
Reliability & 0.324 & 0.486 & 0.563 & 0.689 & 0.745 & 0.896 \\
Economy & 0.429 & 0.495 & 0.562 & 0.663 & 0.783 & 0.909 \\
Finances & 0.401 & 0.488 & 0.589 & 0.697 & 0.731 & 0.899 \\
Overall situation & 0.283 & 0.389 & 0.475 & 0.579 & 0.668 & 0.816 \\
\hline
\end{tabular}


Table 3: Results of competitiveness diagnostics of T Plus, JSC subsidiaries.

\begin{tabular}{|c|c|c|c|c|c|c|c|c|c|c|}
\hline \multirow{2}{*}{\multicolumn{2}{|c|}{$\begin{array}{l}\text { Subsidiary } \\
\text { (heat and power } \\
\text { plant) }\end{array}$}} & \multicolumn{9}{|c|}{ Array of indicators } \\
\hline & & 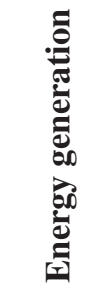 & 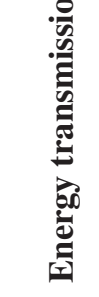 & 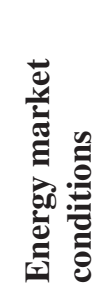 & 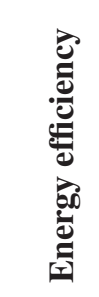 & 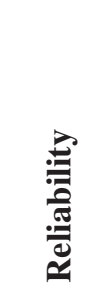 & 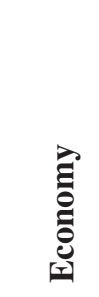 & 冚 & 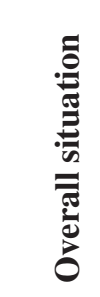 & • \\
\hline \multirow{2}{*}{ Vladimirsky } & $r$ & 0.374 & 0.443 & 0.285 & 0.518 & 0.578 & 0.804 & 0.706 & 0.529 & 8 \\
\hline & $h$ & $C$ & $E$ & $C$ & $E$ & $D$ & $F$ & $E$ & $D$ & \\
\hline \multirow{2}{*}{ Nizhegorodsky } & $r$ & 0.337 & 0.182 & 0.452 & 0.530 & 0.527 & 0.499 & 0.425 & 0.422 & 3 \\
\hline & $h$ & $C$ & B & $D$ & $E$ & $C$ & $C$ & $B$ & $C$ & \\
\hline \multirow{2}{*}{ Kirovsky } & $r$ & 0.389 & 0.458 & 0.387 & 0.563 & 0.672 & 0.699 & 0.683 & 0.550 & 7 \\
\hline & $h$ & $C$ & $E$ & $D$ & $E$ & $D$ & $E$ & $D$ & $D$ & \\
\hline \multirow{2}{*}{ Mordovsky } & $r$ & 0.296 & 0.412 & 0.634 & 0.729 & 0.839 & 0.972 & 0.916 & 0.685 & 12 \\
\hline & $h$ & $B$ & $D$ & $F$ & $F$ & $F$ & $G$ & $G$ & $F$ & \\
\hline \multirow{2}{*}{ Oreburgsky } & $r$ & 0.307 & 0.384 & 0.268 & 0.468 & 0.566 & 0.521 & 0.593 & 0.524 & 6 \\
\hline & $h$ & $B$ & $D$ & C & $D$ & $D$ & $C$ & $D$ & $D$ & \\
\hline \multirow{2}{*}{ Permsky } & $r$ & 0.194 & 0.305 & 0.286 & 0.504 & 0.491 & 0.515 & 0.471 & 0.395 & 2 \\
\hline & $h$ & $B$ & $B$ & $D$ & $D$ & $C$ & $C$ & $B$ & C & \\
\hline \multirow{2}{*}{ Samarsky } & $r$ & 0.226 & 0.316 & 0.438 & 0.403 & 0.492 & 0.672 & 0.598 & 0.499 & 4 \\
\hline & $h$ & B & $C$ & $D$ & $C$ & $C$ & $E$ & $D$ & $D$ & \\
\hline \multirow{2}{*}{ Saratovsky } & $r$ & 0.528 & 0.587 & 0.354 & 0.606 & 0.769 & 0.497 & 0.608 & 0.564 & 9 \\
\hline & $h$ & $D$ & $F$ & $C$ & $E$ & $F$ & $C$ & $D$ & $D$ & \\
\hline \multirow{2}{*}{ Sverdlovsky } & $r$ & 0.203 & 0.164 & 0.271 & 0.408 & 0.502 & 0.432 & 0.478 & 0.351 & 1 \\
\hline & $h$ & $B$ & $B$ & $C$ & $C$ & $C$ & $B$ & $B$ & $B$ & \\
\hline \multirow{2}{*}{ Udmurtsky } & $r$ & 0.334 & 0.406 & 0.520 & 0.402 & 0.654 & 0.526 & 0.709 & 0.507 & 5 \\
\hline & $h$ & $C$ & $D$ & $E$ & $C$ & $D$ & $C$ & $E$ & $D$ & \\
\hline \multirow{2}{*}{ Ulyanovsky } & $r$ & 0.605 & 0.556 & 0.593 & 0.462 & 0.819 & 0.512 & 0.946 & 0.641 & 10 \\
\hline & $h$ & $E$ & $F$ & $F$ & $D$ & $F$ & $C$ & $G$ & $E$ & \\
\hline \multirow{2}{*}{ Komi } & $r$ & 0.634 & 0.577 & 0.502 & 0.624 & 0.804 & 0.872 & 0.924 & 0.705 & 11 \\
\hline & $h$ & $E$ & $F$ & $E$ & $E$ & $F$ & $F$ & $G$ & $F$ & \\
\hline \multirow{2}{*}{$\begin{array}{l}\text { Mari El and } \\
\text { Chuvashia }\end{array}$} & $r$ & 0.502 & 0.621 & 0.755 & 0.715 & 0.788 & 0.915 & 0.989 & 0.755 & 13 \\
\hline & $h$ & $D$ & $F$ & $G$ & $F$ & $F$ & $G$ & $G$ & $F$ & \\
\hline
\end{tabular}

Note: $r$ - calculated value; $h$ - current status. 


\section{CONCLUSIONS}

A comprehensive system of information and analytical support for the competitive development of energy cogeneration systems has been developed. It allows studying the possibilities for implementing the competitive advantages of cogeneration power sources with the help of prime factor decomposition reflecting economic imbalances. In addition, these factors characterize the development risks of various degrees, affecting the competitiveness of cogeneration power sources in the markets of electric and thermal energy. The proposed system makes it possible to monitor the changes in the business environment on a regular basis. Besides, it will allow the company management to timely minimize the development risks and to take advantage of potential opportunities offered by the current market situation.

\section{ACKNOWLEDGEMENT}

The work was supported by Act 211 of the Government of the Russian Federation, Contract No. 02. A03.21.0006, and the Russian Foundation for Basic Research (RFBR), Contract No. 20-010-00886.

\section{REFERENCES}

[1] Domnikov, A., Antipova, E. \& Domnikova, L., Diagnostics of competitiveness of power-generating companies. WIT Transactions on Ecology and the Environment, 222, pp. 27-33, 2019, doi:10.2495/EQ180031

[2] Domnikov, A., Chebotareva, G. \& Khodorovsky M., Unbiased investment risk assessment for energy generating companies: Rating approach. International Journal of Sustainable Development and Planning, 12(7), pp. 1168-1177, 2017. doi:10.2495/ SDP-V12-N7-1168-1177

[3] Domnikov, A., Khomenko, P. \& Khodorovsky, M., Value-based approach to managing the risks of investing in oil and gas business. International Journal of Sustainable Development and Planning, 12(6), pp. 1085-1095, 2017. doi:10.2495/SDP-V12-N6-1085-1095

[4] Domnikov, A., Chebotareva, G., Khomenko, P. \& Khodorovsky, M., Risk-oriented investment in management of oil and gas company value. International Journal of Sustainable Development and Planning, 12(5), pp. 946-955, 2017. doi:10.2495/SDPV12-N5-946-955

[5] Domnikov, A.Y., Antipova, E. \& Domnikova, L., Evaluation of economic risks for power-generating companies. WIT Transactions on Engineering Sciences, 121, pp. 125-133, 2019. doi:10.2495/RISK180111

[6] Domnikov, A., Chebotareva, G. \& Khomenko, P., Risk and profitability optimization of investments in the oil and gas industry. International Journal of Energy Production and Management, 2(3), pp. 263-276, 2017. doi:10.2495/EQ-V2-N3-263-276

[7] Hayek, F., The meaning of competition. Austrian Economics, Hillsdale: Michigan, pp. 264-280, 1991.

[8] Lance, G.N. \& Williams, W.T., A general theory of classificatory sorting strategies. 1. Hierarchical systems. The Computer Journal, 9(4), pp. 373-380, 1967. https://doi. org/10.1093/comjnl/9.4.373

[9] Ward Jr., J.H., Hierarchical grouping to optimize an objective function. Journal of the American Statistical Association, 58(301), pp. 236-244, 1963. https://doi.org/10.1080/ 01621459.1963.10500845

[10] Schroeck, G., ed., Risk Management and Value Creation in Financial Institutions, John Wiley \& Sons, Business \& Economics: England, pp. 47-85, 2002. 
[11] Jardine, N. \& Sibson, R., Mathematical Taxonomy, John Wiley and Sons: London, 286 p., 1971.

[12] Hartigan, J.A., Clustering Algorithms, Wiley: New York, 351 p., 1975.

[13] Gordon, A.D., Identifying genuine clusters in a classification. Computational Statistics and Data Analysis, 18(5), pp. 561-581, 1994. https://doi.org/10.1016/0167-9473(94)90085-x 